\title{
Research on Accounting Informatization Management Strategy Under Enterprise Financial Sharing Service
}

\author{
Chunxia Chen
}

\author{
Dongying Vocational College, Dongying, Shandong, 257091, China \\ Email: chenchunxia76@163.com
}

\begin{abstract}
In the fierce market competition, enterprises need to combine their own actual situation, attach great importance to financial sharing. Based on the analysis of the advantages and innovative modes of financial sharing service, this paper further clarifies the key points of financial sharing, and guides the daily operation and financial management of enterprises. In the new historical period, it is necessary to reform and innovate the financial sharing work of enterprises, to make up for the insufficiency in the construction of the financial sharing service mode of enterprises, to establish and perfect the accounting information management system, to organize and carry out the accounting reform and innovation work of enterprises, and to further promote the sustainable development of the financial information of enterprises.
\end{abstract}

Keywords: enterprise finance, shared service, accounting informatization, enterprise development.

\section{INTRODUCTION}

The application of Internet, mobile communication, cloud computing, big data and other technologies has stimulated the development of the network era and the arrival of the era of knowledge economy[1-3], accelerated the pace of accounting information integration into the information society, and the accounting informatization is developing at a high speed in the direction of standardization, intelligence, interconnection and socialization, which has greatly improved the accounting work efficiency and management level[4], expanded the field of accounting data and improved the quality of accounting information. How to seize the opportunity, overcome the challenge and improve the level of accounting informationization is an urgent task. Therefore, it is necessary to study the accounting informationization management strategy.

\section{OVERVIEW OF ENTERPRISE FINANCIAL SHARING SERVICE MODE}

\subsection{The concept of enterprise financial sharing services.}

Shared service is a new management mode based on customer demand, which provides professional shared service for business units and external enterprises according to market price and service level agreement. Concretely, by integrating some repetitive business units into a single profit center, the shared service enables enterprises to put limited resources and main energy into their core business, create and maintain their own advantages, and finally achieve the goal of integrating resources, reducing costs and improving efficiency. Shared services model provides services related to finance, fund management, marketing, human resources, procurement, information technology, taxation and logistics. Enterprise Financial Sharing Service (FSSC) refers to the internal establishment of a department within an enterprise to centralize the accounting business scattered in different places into one center for processing, and to provide financial services based on process and data for the subsidiaries or business departments of the enterprise group, so as to reduce costs and improve efficiency ${ }^{[5]}$. It is a kind of accounting and reporting business management method that has appeared and become popular in recent years. It ensures the uniformity and standardization of accounting records and reports by using a shared service center for the bookkeeping and reporting of entity accounting transactions in different countries and regions. 


\subsection{Necessity of building enterprise financial sharing service}

(1) The enterprise financial sharing service mode is conducive to realizing the development strategy of the enterprise. The design of financial accounting and management mode of enterprises is to realize the financial warfare of enterprises.

(2) Optimize the financial audit environment. First of all, financial management needs to strengthen communication and exchange with other departments, to further obtain the support of other departments, which is the key to effective financial management of financial sharing. Secondly, to publicize the importance of financial audit and strive for the recognition and support of financial sharing from all walks of life. Thirdly, the financial management department should take the initiative to communicate with the law enforcement organs. In the process of financial audit, the major violations of discipline and law should be transferred to the discipline inspection and judicial organs in a timely manner to effectively play the role of supervision of the audit work.

(3) Establish and improve the financial audit management system. In the new historical period, in order to ensure that enterprises meet the needs of financial sharing, financial management departments need to establish and improve the financial audit system, improve the efficiency of the use of funds. In order to meet the needs of the market, enterprises need to expand the scale of production. In this case, the financial management department needs to take measures to improve the traditional financial audit management system. At the same time, with the continuous expansion of the scale of production, the number of enterprise personnel increased sharply, then put forward higher requirements for the quality of grass-roots management personnel. Through the establishment and improvement of the audit management system, to help financial management departments improve audit management capabilities and audit efficiency, and to a certain extent to guide financial sharing[6].

(4) Clarify the focus of financial sharing and improve the quality of audit work. In the fierce market competition, in order to achieve their own survival and development, enterprises need to study and analyze the difficulties of financial sharing in the process of operation, and at the same time, in the organization and development of financial sharing, focus on financial sharing, and give some artificial tilt. In order to effectively use the existing funds of an enterprise, in the process of using the funds, it is necessary to meet the actual needs of the financial sharing work, and take measures to ensure the legality of the use of the funds, and at the same time, earnestly maintain the scientificity and reasonableness of the use of the funds by means of budget, audit, etc. In the new historical conditions, in order to help the audit department achieve the goal of financial sharing, we need to comprehensively analyze the difficulties in financial sharing, further clarify the content of financial sharing, and on this basis, focus on doing a good job in financial audit, audit of special funds[7].

\subsection{Advantages of enterprise financial sharing service mode}

(1) Improve work efficiency and information quality of enterprise departments

In the traditional financial management mode, there are many problems, such as different management level, unstandardized accounting, and low efficiency, which can not provide accurate data support for enterprises. Financial Sharing Service Model Through the use of modern computer information technology, the business processes of all departments of the enterprise are standardized, and a platform for unified accounting and management of various business data is provided, thus the daily complex or repetitive work of the enterprise is simply standardized. Under the new model, the division of labor among departments and internal personnel is more meticulous, from the business layer to the management layer, realizing the centralized management and sharing of information resources, greatly improving the work efficiency and information quality, and providing timely and accurate financial data for enterprises.

\section{(2) Reduce enterprise management costs}

Under the management of financial sharing service mode, more information technology is used to complete the data collation and accounting, compared with the traditional financial management mode, under the same business workload, only a small number of personnel can complete. In the case of increasing business volume, there is no need to increase more personnel, which greatly reduces the labor costs of enterprises. From the data input of business layer to the completion of approval to generate financial data, electronic information processing can be used to avoid the repetition of the previous paper process, saving time and cost significantly.

\section{(3) Strengthen enterprise risk prevention and control}

The financial sharing service mode breaks the geographical limitation of the enterprise and realizes the centralized processing of financial data and business information among the branches of the enterprise. Through the formulation of risk standards in the system, the risk management of enterprises can be transparent and standardized, and enterprises can monitor abnormal business data and risk points at any time in the operation process, so as to timely and effectively take 
corresponding preventive measures to control various risks.

\section{(4) Enhancing the competitiveness of enterprises}

Under the new financial management mode, not only the work efficiency of the enterprise staff has been effectively improved, but also the obtained financial data and business information resources are of high quality and strong authenticity, which provides more powerful data support for the management of the enterprise to analyze and make decisions and make business strategies, realizes the integrated operation of business and finance, greatly reduces the management cost of the enterprise, creates greater economic benefits and makes the enterprise more advantageous in the market competition.

\subsection{Problems and Causes in the Construction of Enterprise Financial Sharing Service Mode}

(1) The financial sharing service model is not perfect

In the initial stage of building the financial sharing service mode, we will always find that there are various problems in the system, almost every business link has shortcomings and needs to improve. Because each enterprise group's organizational structure and business processes are not the same, it is not easy to establish a financial sharing service model in line with a certain enterprise group. The financial sharing model involves more business modules, and the process of each business may be diversified. Building a complete financial sharing service model suitable for an enterprise group is not a one-time task, but a staff member who needs the participation of the enterprise discovers problems in the application process and uses computer information technology to gradually improve the system.

(2) Inadequate capacity of financial sharing service personnel

After the implementation of financial sharing service mode, the business process will become simpler and more standardized than the traditional financial system, but it requires more professional staff. Because the financial sharing service model involves the big data, the informationization and so on the high and new science and technology, also proposed the higher ability request to the financial personnel. The work of financial personnel has changed from post-accounting and supervision to pre-forecasting and analysis of the front end of the business, which enhances the functions of financial personnel. Some financial personnel are accustomed to the working process of the traditional mode and do not have the corresponding professional ability to adapt to the new mode, so they may worry about the deterioration of their business ability, lack of promotion channels or low salaries, which may lead to the decrease of their enthusiasm for work. Shared finance requires solid financial handlers and high professional quality management staff to provide efficient and quality support services, while business finance requires financial understanding and thinking from a business perspective in order to support the business.

(3) Unreasonable business processes of various departments of the enterprise

The establishment of financial sharing service mode means the reorganization of enterprise's organization structure and business process. There is no unified standard mode for different enterprises. Many enterprises standardize the new business standard flow when the new mode is established, which can not suit the business characteristics of the enterprise once and for all, the coordination and sharing mechanism among various departments is not perfect, and the business process personnel are in conflict with the new mode, which all affect the construction of the financial sharing service mode to a great extent.

(4) Unsound performance assessment and guarantee system

Many enterprises implement the new financial sharing service model, and did not formulate the corresponding performance assessment and security system, or there is, but it is only a formality, and did not play its due role. Without the performance evaluation and guarantee system adaptable to the new financial sharing service mode, it is impossible to supervise and manage the implementation of the new financial sharing service mode in an all-round way, and there is no due restraint and incentive for relevant personnel.

\subsection{Accounting Informatization Mode under Enterprise Financial Sharing Service Mode}

(1) Optimize the financial sharing service mode and enhance the informatization level of enterprises

The financial sharing service mode includes a wide range of business, complex process, large amount of data and information, and the complexity of the platform makes the system need to be improved a lot. In order to build a perfect financial sharing service model in line with an enterprise group, the key is to optimize the specific business processes of the enterprise. The enterprise shall, in light of its actual situation, institutionalize and standardize the processes, integrate them into the service system, and use data processing information technology. In the process of application, the enterprise shall constantly optimize the accounting system, improve the level of information technology and give full play to the functional role of the financial sharing service model. 
(2) Cultivate or introduce professional talents and improve the post competence of personnel

Whether the staff have professional knowledge will directly affect the effect of building financial sharing service model in the early and late continuous operation. Financial personnel can only improve the ability to master the company's business knowledge, go deep into the front end of the company's business, and feedback the important financial forecast and analysis information to the company's business personnel by using their professional knowledge. The relevant personnel of the financial department shall actively learn to use different management tools and methods to effectively combine with data and information so as to provide higher quality and effective information for the company to handle business. Therefore, while implementing the financial sharing model, enterprises need to standardize and unify the training path of financial personnel, formulate a long-term plan for the building of financial personnel, and form a long-term training mechanism. When necessary, relevant professionals shall be directly introduced from the outside, so as to ensure that the personnel are competent for their own posts.

(3) Standardize the internal business processes of enterprises and clarify the responsibilities of department personnel

In order to build an internal business process suitable for the financial sharing service mode of an enterprise, the responsibilities and relationship between finance and business shall be defined first, and the process plan for the relevant business shall be formulated based on the business perspective of the enterprise, and then the corresponding process standards shall be formulated according to the business characteristics of each business unit, and the responsibilities of the personnel of all departments and posts shall be defined. During the implementation of the new mode, the system shall be continuously optimized and improved according to the changes in the internal and external environment of the enterprise and the management needs. The establishment of the financial sharing service mode is the process of optimizing and improving the financial management process, discovering and solving the problems in the later period, so that it can run stably and efficiently.

(4) Perfecting the corresponding performance appraisal system, and establishing organizational guarantee departments

In the process of constructing the financial sharing service mode, unified and standardized financial operation standards and systems shall be formulated, the performance appraisal system for each post and each process shall be improved, and corresponding punishment and incentive measures shall be formulated, so as to enhance the sense of responsibility and enhance the enthusiasm of the staff of each department. Set up relevant organization guarantee department to supervise and manage the operation process and results of each department under the new financial sharing service mode, and ensure the actual work of relevant organizations and departments meet the requirements of enterprise development.

\section{ACCOUNTING INFORMATION MANAGEMENT STRATEGY UNDER ENTERPRISE FINANCIAL SHARING SERVICE}

\subsection{Raise strategic awareness and optimize the overall framework.}

In 2006, the State Council printed and distributed the National Informatization Development Strategy, 20062020, the Ministry of Finance promulgated the Guiding Opinions on Comprehensively Promoting the Accounting Informatization Work of our Country in 2009, and the Ministry of Finance promulgated the Regulations on Accounting Informatization Work of Enterprises in 2013. Under the guidance and promotion of the State, the accounting industry of our country has experienced rapid development from computerized accounting to accounting informatization. Enterprises have complied with the trend of economic and technological development and the development requirements of the capital market, widely adopted ERP integration software based on the needs of business management, realized the integration of financial and business, and improved the management, control and decision-making capabilities of enterprises. However, due to the different intellectual property rights protection, data collection standards and storage and transfer-out formats, various software cannot be compatible with each other, and many enterprises have emerged that the data between such systems as the enterprise resource planning system (ERP), the customer relationship management system (CRM), the supply chain management system (SCM) and the office automation system (OA) cannot be naturally connected, and cannot effectively provide comprehensive information across departments and systems. Accounting information system is the core subsystem of enterprise management information system, producing more than $70 \%$ of enterprise information. Accounting informatization is the basis and organic part of enterprise informatization and national informatization. Under the background of increasingly fierce global competition and informatization as the core competitiveness of the market, enterprises must take a forward-looking view, attach importance to informatization work with international strategic thinking, comprehensively consider the construction and coordinated development of various informatization 
systems within enterprises, avoid repeated investment, repeated construction, low efficiency and the occurrence of isolated accounting information, incorporate accounting informatization into the overall construction of enterprise management informatization, closely combine it with national informatization, make overall planning, implement national standards and unified data interfaces, implement standardization and standardization of basic data collection, improve the universality, openness, accuracy and stability of information, realize the automatic connection and safe and fluent exchange of data among various software systems, strive to achieve the goal of outgoing number, resource sharing, and improve the level of deep processing and reuse of data, so as to improve the management level of accounting informatization and the comprehensive competitiveness of enterprises.

\subsection{Implementing security strategies strengthening internal control.}

and

Today's society has entered an information age characterized by digitalization, networking and intelligence. With the extensive adoption of new technologies and new carriers, enterprises have generally used a highly integrated and networked distributed system structure, which has improved the efficiency of accounting information collection and collation and the speed of data transmission feedback. At the same time, the accounting information system has gradually become an open system by widely receiving and sending the information of financial and non-financial indicators, exchanging data in real time, and obtaining information from each other through the information interface transformation of various institutions and departments inside and outside the enterprise. Due to the distributed, open and remoteprocessing characteristics of the accounting information system, the unity and controllability of the system are greatly reduced, and the system is more vulnerable to attacks from hackers, malicious software, virus Trojans, phishing sites, etc., innovation must be made in terms of technology and system so as to ensure the security of the network and information.

(1) Implementing operational safety technology strategies. First, implement security technology control. Instead of replacing servers with ordinary office computers, special accounting servers shall be purchased, firewalls and routers shall be added, and a comprehensive multi-layer three-dimensional security system shall be established by using access control technology, data encryption technology, tunnel technology, etc., so as to restrict the outside illegal access to the server of the special accounting network application system and the accounting database system and effectively prevent external intrusion. Second, run system security policies. Using the security strategy of operating system, database management system and accounting software system, the security of accounting data can be ensured by establishing reasonable user account, authority and password, authorization of network resources access and identity authentication. Once more, strengthens the network information security technology examination. Install genuine antivirus software and system detection tools, such as 360 anti-virus and security guard software, carry out realtime protection of accounting information system, give real-time warning of network attacks and fraud, promptly and effectively eliminate potential viruses, improve network theft detection and early warning ability and network harmful information monitoring ability; promptly make online repair of system security loopholes and upgrade software to prevent pre-existing problems, thereby improving the security of the entire system.

(2) Strengthen the system internal control system. First, establish rules and regulations. In accordance with the principle of "mutual separation and mutual restriction", a series of control systems such as scientific prevention of computer viruses, software development and maintenance, hardware management and maintenance, organization of organizations and personnel, and resource information management shall be formulated to ensure the safe operation of the accounting information system. Secondly, strictly implement the authorization and approval control system. System administrators are mainly responsible for the management and maintenance of hardware and software systems and the allocation of user authority and network resources; operators shall operate in strict accordance with the authorized limit and shall not access the system beyond their authority; system programmers shall not engage in business operations beyond their authority. By clarifying the post responsibility of system administrator, operator and programmer, and defining a reasonable scope of authority, the unnecessary loss and risk can be avoided. Thirdly, establish safety audit and internal audit system. Implant the financial monitoring mechanism based on business process into the informatization system, attach importance to the control and inspection of "key posts" and "key points" in the business process, regularly or irregularly audit the organizational control, system maintenance control, system security control, operation control and other links of accounting, objectively evaluate the security status of the accounting informatization system, and put forward improvement measures and emergency plans.

\subsection{Improve the file management and raise the use efficiency}

(1) Attach great importance to the work of accounting archives. The construction of archive 
infrastructure is the material basis and premise to ensure the development of accounting archive work. Enterprises shall, according to their own actual needs, provide warehouses that meet the requirements of archive management, configure basic hardware and software systems such as computers, air-conditioners, dehumidifiers and dust collectors necessary for archive management, and equip full-time or part-time accounting archive personnel. Establish a system for handover, filing, safekeeping, retrieval and destruction of accounting records. In strict accordance with the provisions of the system, access to accounting records shall be conducted according to authority, necessary examination and approval procedures shall be performed, access to accounting records shall be standardized, and accounting records whose custody period has expired shall be regularly destroyed, so as to relieve the pressure of warehouse management.

(2) Do a good job in the daily work of accounting archives. Synchronized filing of paper and electronic archives shall be implemented to improve the insurance coefficient of archives. According to the physical characteristics of the information carrier, the electronic documents shall be prepared in duplicate, that is, the data shall be backed up and archived by adopting the "AB" backup method, and shall be stored on the photoelectric medium instead of magnetic medium as much as possible. Away from the magnetic field, remote storage, pay attention to moisture-proof, dust-proof, so that when the system is damaged, can be emergency response, rapid reconstruction and rapid recovery. In order to meet the needs of compatibility of alternate generation data, future inquiry and failure recovery, different versions of accounting software and system software shall be archived simultaneously, and the version of accounting software and system software corresponding to the backed up data shall be indicated. It can also be used to export the accounting vouchers, general ledger and detailed ledger, and save and archive them in Excel or Access for direct access and inquiry in the future. The index system of accounting materials shall be established to ensure the improvement and upgrading of the linear and interrelated work systems of accounting materials so as to comprehensively enhance the efficiency of financial management and realize high quality and efficient management. On the one hand, departments shall attach great importance to the functions of the financial management system, establish a set of thoughtful management measures and operation process guidelines for planning management measures, improve the practicability of the system, and ensure the smooth development of cashier work. On the other hand, the functional departments and personnel in charge of the cashier work must abide by the professional norms, and ensure that the systems and regulations can play their basic functions in the implementation of the work, so as to strengthen the cashier work, promote the management work to obtain a new development space, obtain a greater breakthrough, and then achieve the goal of strengthening the cashier work efficiency.

(3) Enhancing risk awareness and improving financial management risk control levelFinancial management risks are divided into two major aspects: risks within the scope of macro mechanism and risks in micro mechanism. Both of them are interdependent. It is far from enough to talk about risk control only in the macroscopic scope. Similarly, it is unilateral to talk about risk in the microscopic mechanism. In fact, macroscopic mechanism and microscopic mechanism are the inseparable structure in the financial management risk control. If we emphasize the importance unilaterally, there is a certain risk in itself. Practice tells us that we must correctly understand the relationship between macro mechanism and micro mechanism, strengthen the risk control awareness, and based on reality, research and create the corresponding theory and method, in order to further improve the level of financial management risk control. In this process, we can establish a coordination mechanism, that is, to reach a consensus among the financial management departments, for some suspicious operations of borrowing in different places, on-site inspection, to prevent the wrong operation of borrowing in different places.

(4) Standardizing operational procedures and improving work capacity

1). Standardize the cashier operation procedures. The procedures for cashier work are interrelated. The cashier shall tighten the control over all procedures, strictly supervise and control the expenditure amount and use scope of the funds, and check and verify the data and materials on a daily basis. The cashier shall regularly check and clear the bank deposits and loans, and prepare a reference book according to the check results, so as to ensure the safety, liquidity and efficiency of the fund flow and minimize the financial risks. In addition, expenditures relating to loan reimbursement shall be handled in strict accordance with the relevant standard procedures and follow the control procedures such as application for authorization, approval with seal, execution with signature, careful recording and careful inspection; expenditures that do not meet the standards and requirements shall not be accepted, so as to ensure the completeness, preciseness and accuracy of business processes.

2). Improve the operational capacity of cashiers. The cashier work of the department is a systematic, complicated and exquisite engineering activity. In order to do this work well, we must strengthen the construction of the quality of the cashiers, improve their work consciousness and professional ability, and require them to do "Three Attentions, Four Minds" in daily 
activities. Three ground ": First, the business does not need to ask." For some important business to report to the leadership. Second, the handling of business to hand ground. For business matters for which they are responsible, they shall be diligent in inspection, ensure proper completion of forms, accurate counting of notes, prompt bookkeeping, clear formalities, particularly for each transaction of receipt and payment of funds, the cash journal and bank deposit journal shall be progressively recorded in accordance with chronological sequence, inventory shall be taken promptly, daily and monthly settlement shall be made, and the accounts shall be consistent. Third, contact the bank to leg ground. Cash deposits in excess of the prescribed limit shall be deposited in a timely manner, and the bank accounts shall be checked with the bank frequently. Once any inconsistency is found, the situation shall be clarified and corrected promptly. Four Hearts: First, learn business with an open mind. With regard to some business and problems that they do not understand, they shall consult their experienced colleagues with an open mind, and shall not pretend to understand them. In the current background of in-depth advancement of information technology, cashiers still need to constantly strengthen learning, supplement their own knowledge reserves, and arm their minds with scientific and theoretical knowledge to meet the needs of information construction of cashier work. Second, treat the work attentively. Under the new economic situation, the cashier's work begins to show the characteristics of different means and nature, which requires the cashier to have a progressive heart, and establish a correct outlook on life and values, stick to the work post, constantly sum up the experience of the work, and achieve the innovation of keeping pace with the times. Third, carefully handle business. Cashiers deal with money in a recurring way every day, handling, keeping, receiving and paying a large amount of monetary funds and bills, if there is a mistake in a certain link, it is very likely to bring losses to the country, departments, units and individuals. Only do a good job in the cashier, to ensure the safety of monetary funds, to prevent loss and waste of funds, so as to improve the efficiency of the use of funds. Fourth, enthusiastic service personnel. Cashiers must firmly establish the idea of serving the vast number of personnel and provide them with warm and thoughtful service in order to play a good role in safeguarding the cashier's work.

\section{CONCLUSION}

The Internet has changed the traditional accounting method and data storage form, and triggered the innovation of financial management mode and enterprise strategic decision. For scale enterprises, the traditional financial management mode can no longer meet the needs of development. Therefore, it is necessary to make full use of the specialized division of labor information system, establish the financial sharing service mode, take it as an important means for enterprises to improve efficiency, create value and save cost, build an efficient informatization framework from a strategic height, strengthen network security risk prevention, ensure data security and improve the level of comprehensive utilization of information, which is the goal and key strategy of accounting informatization management to adapt to the rapid development of market economy.

\section{REFERENCES}

[1] YAO, LU. Financial accounting intelligence management of internet of things enterprises based on data mining algorithm[J]. Journal of intelligent \& fuzzy systems: Applications in Engineering and Technology,2019,37(5 Pt.1):5915-5923.

[2] BRADFORD, WILLIAM, CHEN, et al. The effect of corporate governance on credit ratings: Evidence from China's bond market[J]. Journal of international financial management \& accounting,2019,30(2):113-144.

[3] RIIKKA MAARIT HOLOPAINEN, MERVI NISKANEN, SARI RISSANEN. Management Accounting and Profitability in Private Healthcare SMEs[J]. International Journal of Public and Private Perspectives on Healthcare, Culture, and the Environment.,2019,3(1):28-44.

[4] WANCHAO LIU. How Useful Is It for Banks to Analyze Financial Statements[J]. American Journal of Industrial and Business Management,2020,10(08):1488-1504.

[5] SHERESHEVA, MARINA, VALITOVA, LILIA, TSENZHARIK, MARIA, et al. Industrial LifeCycle and the Development of the Russian Tourism Industry[J]. Journal of Risk and Financial Management,2020,13(6):113.

[6] ALINA CIUHUREANU. Study on the Opportunities and Limitations of How to use the Information Provided by Financial Accountancy[J]. Land Forces Academy Review,2019,24(3):220-225.

[7] MALCOLM CAMPBELL-VERDUYN, MARCEL GOGUEN, TONY PORTER. Finding fault lines in long chains of financial information[J]. Review of International Political Economy,2019,26(5):911937. 